\title{
Emergency Vehicle Priority Based System
}

\author{
Sarfraz Ahmad, K. C. Maurya
}

Department of Computer Science and Engineering, Integral University, Lucknow, Uttar Pradesh, India

\begin{abstract}
Article Info

Volume 7, Issue 4

Page Number: 377-382

Publication Issue :

July-August-2021

\section{Article History}

Accepted : 20 July 2021

Published : 27 July 2021

Every country's vehicular traffic is increasing, growing, and there is terrible traffic congestion at intersections. In the current case, most traffic lights have a fixed light sequence, so green light sequence is to determine with-out taking priority vehicles into account. As a result, priority crews such as police cars, ambulances, fire engines are still unable to perform, get stuck in traffic and come in late, which can result in the loss of valuable property and life, which does happen on occasion. The green light sequence is evaluated given the current state of traffic, without taking into account the existence of emergency vehicles. Our aim to this paper is to present a mechanism for scheduling emergency vehicles. It is provided to important such as access control protocol to convey emergency vehicle information to the Traffic Management Center (TMC) with time delay and to all alerts while using GPS techniques for acquiring emergency vehicle information. Only then is the emergency vehicle quickly dispatched, and the destination is reached on time. It would be helpful in the future for the prominence of casual vehicles.

Keywords : GPS Tracking Ambulance, formatting, distance measure technique, priority vehicle, emergency lights, control traffic monitor for priority based.
\end{abstract}

\section{INTRODUCTION}

In every intelligent traffic management system, traffic light control is critical. In traffic light monitoring, the sequence of green lights and the length of green lights are the two most significant variables to consider. Most traffic lights in many countries include fixed light sequence and light time duration. Priority crews methods, but at the other hand, are suitable for secure or normal traffic, not for dynamic traffic. In the present state of operation, the sequence of green light is established with-out taking into account the possibility of the presence for emergency priority vehicle. As a response, emergency vehicles such as , police cars, fire trucks, ambulances and other types of emergency vehicles wait in traffic points at intersection, avoiding their arrivals at particular result and destination in the loss of life and property. Ireland, an average of 700 fatalities was noted every year due to come late ambulance vehicle responses [1].

Mostly researcher have built pre-emption systems that measure the signal time based on the specific distance in between emergency vehicle and intersection. Our present a new and unique approach for calculating distance in between an emergency vehicle and an intersection use a real time data feed 
from intersection sender response in this paper. Our aim is to install another lighting in addition to the green light, in which we are proposing a new blue light to them without disturbing the traffic rules and their control system.

Through this, when this emergency vehicle has to be removed from traffic, only this new blue light will be used. To target emergency vehicles, a range of traffic control systems have been introduced [4]. The maximum part of this research has been based on the design of an intelligent traffic control system to provide vehicle evacuation systems in the event of an emergency. (5),(6),(7)

\section{Background}

(GPS) Global Positioning System is a space/cloud based satellite navigation system. It gives all the environmental conditions in one place and also shows the traffic conditions on the road. This technology is based on social networking, wherever the driver is, GPS tells its real location.

The function of GPS is to help identify two or more satellites and measure their distance and calculate their actual position using the information received. The term microcontroller usually refers to a complete system consisting of three main components: first, it operates purely on the basis of an operating system, allowing any real operation to be implemented from the system it receives. Second, it can be used with any system using the technology, with which the storage of data and applications can also be configured.

Raspberry $\mathrm{Pi}$ is a type of operating system or it can also be called micro electronic device, using which any real work can be done by the operation of a new program through some technology.

Depending on the application, the GPS will usually be able to take some type of data and generate a map between those two locations.
To find out the actual presence of the vehicle we use GPS, which is known as a sort of interrogator.

1. As the number of vehicles on the road continues to increase, traffic congestion and transportation delays occur in many countries around the world. Fire trucks, ambulances and police cars, for example, should be able to respond to emergency calls as quickly as possible. The quality of an emergency response is determined by how quickly emergency vehicles can arrive at the scene of an incident. If an emergency vehicle becomes trapped in traffic and takes longer to arrive at the scene of the crash, lives and property can be lost. According to the future times, density based smart traffic system is needed keeping in mind the priority and traffic to make the transportation efficiency and emergency action timely.

2. A great deal of research has gone into determining whether to use traffic data in a good way to assess green light sequences, and control the number of transport vehicles at traffic points. An innovative series of traffic control systems have been introduced for accidental prioritization of vehicles in the event of an emergency [4]. Majority of this research is based on intelligent traffic control system architecture for providing emergency vehicle clearance [5-9]. Cameras are used to calculate traffic conditions, and lane center edges are used to estimate traffic parameters [10] [11].

3. Strobe emitter, or light emitter, is used in traffic systems to detect issues such as blocked lines of vision and unnecessary traffic noise [12]. (IR) Infrared and (GPS) Technologies like the Global Positioning System have been used by us to track emergency vehicle presence and to measure the density of traffic in real-time. [13].

The inductive loop approach has been used to count vehicles at traffic points and RFID has been used to check for the presence of emergency vehicles.[14] Radar detection, Video based tracking system, ultrasonic detection and other types of traffic detection are commonly used. 


\section{Proposed Methodology}

To get rid of this problem and for the convenience of the public, this technical system can be used. Which will give priority to accidental vehicles in the coming time. This system at the traffic signal will help the accidental vehicles to reach their destination.

a) As the driver uses this application, his actual location will be known, where the driver will receive the patient, and as soon as he determines where he needs to go, a map between the two locations of the sender and the receiver will be displayed via GPS.

b) It will be displayed on the mobile screen by the registered number of the driver along with the image.

c) This data which will be received from sender and receiver will be stored in Data base(Fire base).

d) According to the received map, both the locations (generated between sender and receiver) will be received by an API to the microcontroller i.e. Raspberry Pi.

e) The received data will be sent to the TMC under a notification, which will forward the traffic point, to be passed through the microcontroller i.e. Raspberry Pi.

f) According to this system, any accidental vehicle (ambulance, fire, police or others) will pass through the traffic point to register itself. Only then will the data be transferred to TMC through cloud storage. After approaching Data TMC, he orders the vehicle to reach its destination by sending the data to the vehicle, traffic point according to the data received through GPS, the vehicle's position.

g) The State shall, pursuant to this State Notification, turn on sirens with blue lights at traffic point intersections, so that accidental vehicles may pass through that intersection without being caught in traffic.

h) Whatever time the vehicle takes to reach its destination and the data received, that data will be stored for future use.

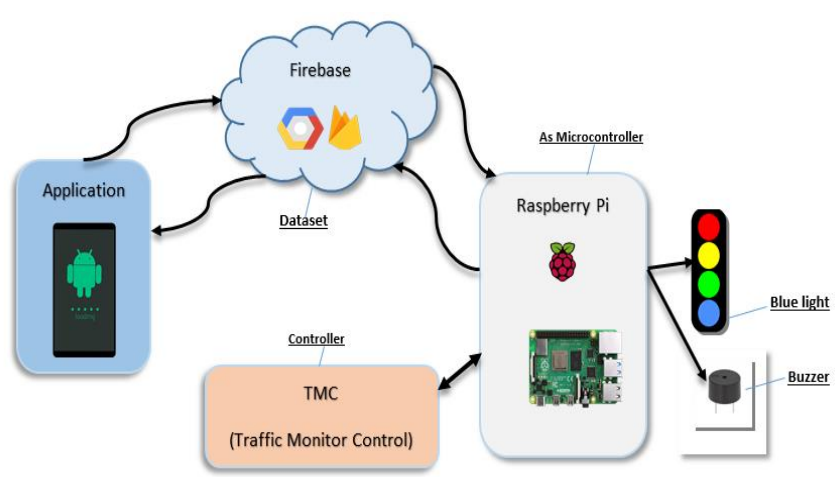

Figure 1. EVPS Architecture img.

The proposed two units are included on this basis. Namely:

- Application unit

- Junction unit (Traffic Signal Point)

\section{Application Unit:}

$\checkmark$ A GPS receiver and a transceiver that works in agreement with a micro-controller and creates a vehicle unit, which will be shared with the vehicle's driver's mobile device.

$\checkmark \quad$ This application will be helpful in working in data control of the driver and TMC. Its basic purpose would be to allow casual vehicles to proceed without stopping at intersections with traffic points through signals. This signal will inform the TMC about the oncoming vehicle through notification. TMC can send signal by receiving notification which it will be able to automate the traffic light at the signal.

$\checkmark$ The application will generate a map of the receiving location and the destination to be taken, which will act as an index to the driver.

\section{Components}

1. Microcontroller: Raspberry Pi,

2. Data Base (Firebase)

3. Application

Junction unit: The interceptor with a microcontroller creates a transceiver called the junction box, which will be present at the post of the traffic signal. The transceiver will receive the GPS coordinates transmitted by the vehicle unit. The junction box's microcontroller software approves the given 
coordinates of a point at a certain distance, turning the traffic signal blue when it is being traversed by the vehicle. Simultaneously, the LED screen displays a message that the accidental vehicle is approaching, indicating that other drivers must be informed of an oncoming accidental vehicle from a buzzer at the traffic point. The vehicle's destination of arrival may vary depending on the traffic landscape at each junction and can be programmed accordingly, giving the green light enough time to remain green before ambulances pass through the intersection. So according to this case the buzzer starts ringing moments before the vehicle arrives, by informing the emergency vehicle through TMC at the approaching intersection. Accordingly, an incoming emergency vehicle such as an ambulance may be present in more than one lane of the intersection.

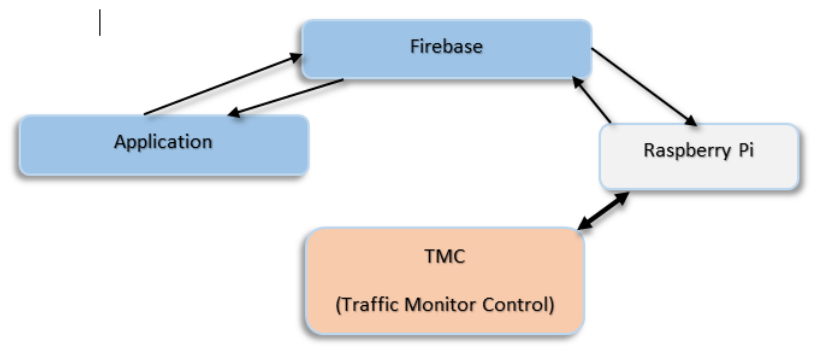

Figure 2 : DFD 0 level components

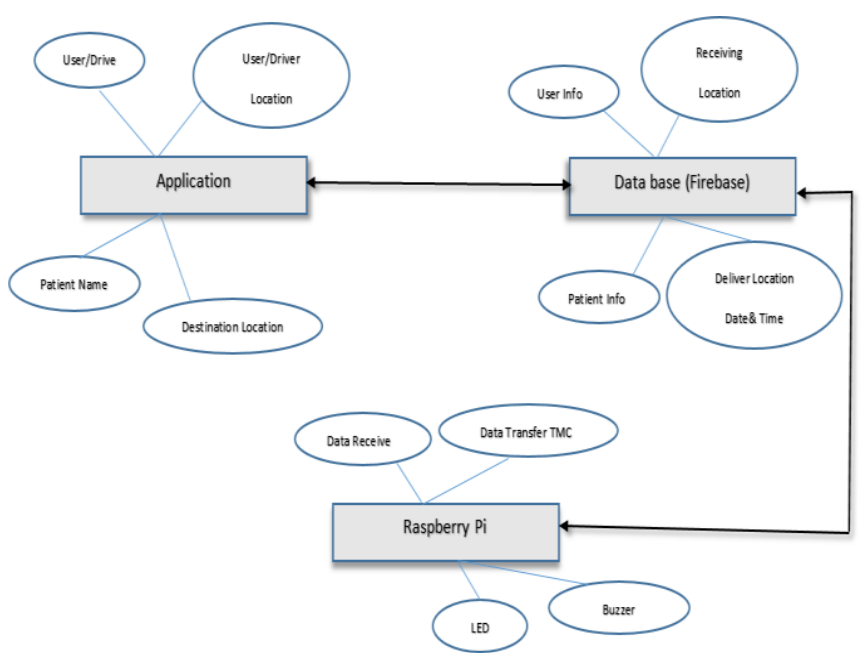

Figure 3 : DFD $1^{\text {st }}$ level components

\section{Simulation and Comparison}

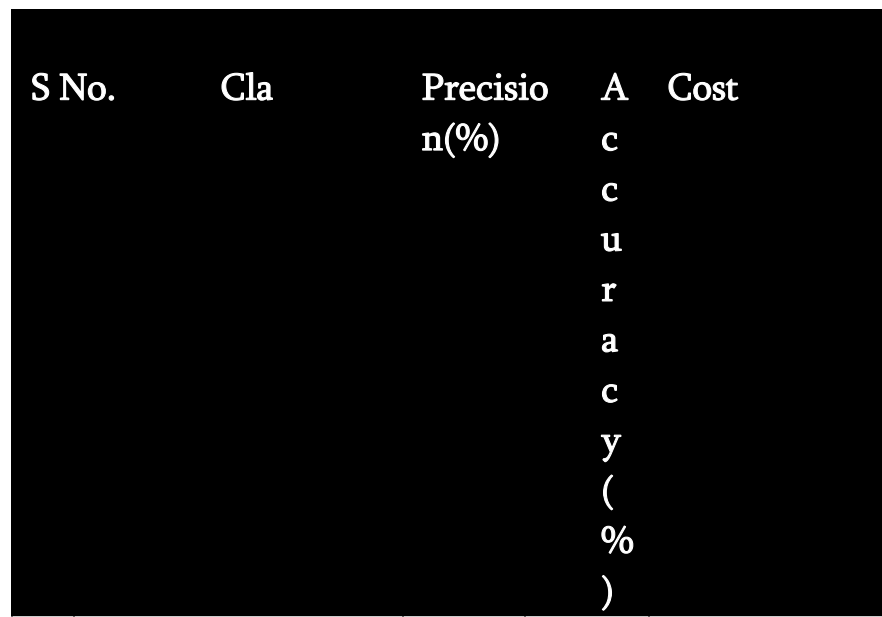

\begin{tabular}{|c|c|c|c|c|}
\hline 1 & $\begin{array}{l}\text { EVPS(Emergency } \\
\text { Vehicle Priority } \\
\text { based System) } \\
\text { Firebase, } \\
\text { Respberry Pi }\end{array}$ & 97 & 95.5 & $\begin{array}{l}\text { non } \\
\text { Effective }\end{array}$ \\
\hline 2 & $\begin{array}{l}\text { Traffic Control } \\
\text { Unit (TCU), } \\
\text { Monitor Unit } \\
\text { (MU) and Road } \\
\text { Side Unit (RSU). }\end{array}$ & 85.5 & 70 & Effective \\
\hline $\begin{array}{l}3 \\
.\end{array}$ & $\begin{array}{l}\text { RFID (radio } \\
\text { frequency } \\
\text { identification) } \\
\text { technology to } \\
\text { implement the } \\
\text { Intelligent traffic } \\
\text { signal control. }\end{array}$ & 89.9 & 90.8 & Effective \\
\hline 4 & $\begin{array}{lr}\text { ARM7 } & \text { system- } \\
\text { on-chip } & \text { and GPS } \\
\text { device } & \text { based } \\
\text { system } & \\
\end{array}$ & 91 & 86.7 & Effective \\
\hline 5 & $\begin{array}{l}\text { Traffic Density } \\
\text { Estimation by } \\
\text { Image Processing }\end{array}$ & 85 & 91 & Effective \\
\hline
\end{tabular}

1) It will be an experiment based on an Android application, in which it can be used for the public by paying a one-time cost. With this technology, we can use every vehicle not by tracking any device but from the mobile of the driver.

2) "Road Side Unit (RSU). A Roadside Unit is a DSRC (Dedicated Short Range Communications) transceiver that is mounted along a road or 
pedestrian passageway. In which it takes time to transmit the data. Sometimes there is also a risk of missing data during transmission.

3) An RFID system consists of a tiny radio transponder, a radio receiver and transmitter. In which the cost of installing receiver and transmitter everywhere becomes very big and its maintenance also becomes very expensive.

4) All vehicles have to implant this device using ARM7 (LPC2148) microcontroller, which is a very expensive deal.

5) Under image processing, the vehicle is identified at traffic intersections using a convolution method, but it is visible only to a shortest distance.

\section{Result}

1. This technical system can be used to get rid of the ambulance not getting stuck in the traffic jam and for the convenience of the public. Which will give priority to accidental vehicles in the coming time. This system at traffic signals will help accidental vehicles to reach their destination.

2. Through this system, an accidental vehicle arrival at the traffic point will be informed by sounding a siren with a blue light indicating the signal.

3. It may take time for the public to accept it initially, but having the facility with smooth technology can not be a problem.

4. This will help casual vehicles, and make it easier for ambulances to get through without getting stuck in traffic jams.

5. The use of this system is to give a separate system to the already running traffic system, so that the traffic control system cannot be obstructed.

6. This control will be led by traffic guards at all traffic points which will be passed by traffic control monitors.

\section{Conclusion}

- This vehicle will prove to play an important role for patients under the priority system.
- Health services, more congestion of vehicles, transportation will reduce the inconvenience of the public by demanding its expertise and importance from a higher level and will help them to reach the destination at the right time through this system.

- Less time will be consumed by the operator and more distance can be fixed quickly.

- To assess the maximum benefits and cost effectiveness of this intervention are necessary.

- Subsequently, our conclusion image classification method will facilitate more advanced search.

\section{REFERENCES}

[1] Hegde R., Sail R.R., Indira S.M. RFID and GPS based automatic lane clearance system for ambulance. Int. J. Adv. Elect. Electron. Eng. 2013;2:102-107.

[2] Abubakr S.E., Halla O.A., Tahani A.A. A GPS based traffic light pre-emption control system for emergency vehicles; Proceedings of the IEEE International conference on Computing, Electrical and Electronics Engineering; Khartoum, Sudan. 26-28 August 2013; pp. 724729.

[3] 1. Djahel S., Smith N., Wang S., Murphy J. Reducing emergency services response time in smart cities: An advanced adaptive and fuzzy approach; Proceedings of the IEEE First International Smart Cities Conference (ISC2); Guadalajara, Mexico. 25-28 October 2015; pp. 1-8.

[4] National Highway Traffic Safety Administration (NHTSA) and the Economic and Social Impact of Motor Vehicle Crashes. [(accessed on 14 December 2015)]

[5] Statistics on Emergency Vehicle Accidents in the U.S. [(accessed on 5 December 2015)]

[6] . Adnan M.A., Hancke G.P. An Efficient Distributed Localization Algorithm for Wireless Sensor Networks: Based on Smart References 
Sarfraz Ahmad et al Int. J. Sci. Res. Comput. Sci. Eng. Inf. Technol, July-August-2021, 7 (4) : 377-382

Selection Criteria. Int. J. Sens. Netw. 2013;13:94-111.

[7] AI-Ostath N., Selityn F., AI-Roudhan Z., EIAbd M. Implementation of an emergency vehicle to traffic lights communication system; Proceedings of the 7th International Conference on New Technologies, Mobility and Security (NTMS); Paris, France. 27-29 July 2015; pp. 1-5.

[8] Rajeshwari S., Santhoshs H., Varaprasad G. Implementing intelligent traffic control system for congestion control, ambulance clearance and stolen vehicle detection. IEEE Sens. J. 2015;15:1109-1113. [Google Scholar]

[9] Sireesha E., Rakesh D. Intelligent traffic light system to prioritized emergency purpose vehicles based on wireless sensor network. Int. J. Res. Stud. Sci. Eng. Technol. 2014;1:2427. [Google Scholar]

[10] Shruthi K.R., Vinodha K. Priority based traffic lights controller using wireless sensor networks. Int. J. Electron. Signal Syst. 2012;1:58-61. [Google Scholar]

[11] Hussian R., Sandhy S., Vinita S., Sandhya S. WSN applications: Automated intelligent traffic control system using sensors. Int. J. Soft Comput. Eng. 2013;3:77-81. [Google Scholar]

[12] Nabeel M.M., EI-Dien M.F., EI-Kader S.A. Intelligent vehicle recognition based on wireless sensor network. Int. J. Comput. Sci. Issues. 2013;10:164-174. [Google Scholar]

[13] Nellore K., Melingi S.B. Automatic Traffic Monitoring System Using Lane Centre Edges. IOSR J. Eng. 2012;2:1-8. [Google Scholar]

[14] Uddin S.M., Das K.A., Taleb A.M. Real-time area based traffic density estimation by image processing for traffic signal control: Bangladesh perspective; Proceedings of the IEEE International Conference on Electrical Engineering and Information Communication
Technology (ICEEICT); Dhaka, Bangladesh. 2123 May 2015; pp. 1-5. [Google Scholar]

[15] Traffic Signal Preemption for Emergency Vehicles. [(accessed on 5 December 2015)]; Available

online: http://ntl.bts.gov/lib/jpodocs/repts te/14 097 files/14097.pdf.

[16] Farheena S., Chandak B.M. An approach towards traffic management system using density calculation and emergency vehicle alert. IOSR J. Comput. Sci. 2014;4:2427. [Google Scholar]

[17] Bharadwaj R., Deepak J., Baranitharam M., Vaidehi V.V. Efficient dynamic traffic control system using wireless sensor networks; Proceedings of the IEEE International Conference on Recent Trends in Information Technology (ICRTIT); Chennai, India. 25-27 July 2013; pp. 668-673. [Google Scholar]

\section{Cite this article as :}

Sarfraz Ahmad, K. C. Maurya, "Emergency Vehicle Priority Based System", International Journal of Scientific Research in Computer Science, Engineering and Information Technology (IJSRCSEIT), ISSN : 2456-3307, Volume 7 Issue 4, pp. 377-382, JulyAugust 2021. Available at doi : https://doi.org/10.32628/CSEIT217461 Journal URL : https://ijsrcseit.com/CSEIT217461 